Abstract OP0252 - Table 1

\begin{tabular}{|c|c|c|c|c|c|c|c|c|c|c|}
\hline \multirow[t]{2}{*}{ Safety results, $\mathrm{n}^{\mathrm{a}}(\%)$} & \multirow[t]{2}{*}{$\begin{array}{l}\begin{array}{c}\text { Any time post } \\
\text { baseline }\end{array} \\
\mathrm{n}=735\end{array}$} & \multirow[t]{2}{*}{$\begin{array}{c}\text { Year } 0-1 \\
n=735\end{array}$} & \multirow[t]{2}{*}{$\begin{array}{c}\text { Year 1-2 } \\
n=701\end{array}$} & \multirow[t]{2}{*}{$\begin{array}{c}\text { Year 2-3 } \\
n=620\end{array}$} & \multirow[t]{2}{*}{$\begin{array}{c}\text { Year } 3-4 \\
n=514\end{array}$} & \multirow[t]{2}{*}{$\begin{array}{c}\text { Year 4-5 } \\
n=442\end{array}$} & \multirow[t]{2}{*}{$\begin{array}{c}\text { Year 5-6 } \\
n=345\end{array}$} & \multirow[t]{2}{*}{$\begin{array}{c}\text { Year } 6- \\
7 \\
n=219\end{array}$} & \multirow[t]{2}{*}{$\begin{array}{c}\text { Year } 7- \\
8 \\
n=65\end{array}$} & \multirow[t]{2}{*}{$\begin{array}{c}\text { Year } 8 \\
+ \\
n=6\end{array}$} \\
\hline & & & & & & & & & & \\
\hline$\geq 1 \mathrm{AE}$ & $706(96.1)$ & 617 & 502 & 441 & 344 & 261 & 181 & 92 & 26 & 3 \\
\hline & & $(83.9)$ & $(71.6)$ & $(71.1)$ & $(66.9)$ & $(59.0)$ & $(52.5)$ & $(42.0)$ & $(40.0)$ & $(50.0)$ \\
\hline$\geq 1 \mathrm{AE}$ resulting in treatment discontinuation & $69(9.4)$ & $13(1.8)$ & $13(1.9)$ & $20(3.2)$ & $10(1.9)$ & $7(1.6)$ & $5(1.4)$ & 0 & 0 & 0 \\
\hline$\geq 1$ serious $A E$ & $231(31.4)$ & $78(10.6)$ & $58(8.3)$ & $66(10.6)$ & $44(8.6)$ & $27(6.1)$ & $16(4.6)$ & $11(5.0)$ & $1(1.5)$ & 0 \\
\hline Serious infections/infestations & $107(14.6)$ & $36(4.9)$ & $24(3.4)$ & $26(4.2)$ & $17(3.3)$ & $14(3.2)$ & $6(1.7)$ & $5(2.3)$ & $1(1.5)$ & 0 \\
\hline Infections of special interest ${ }^{\mathrm{b}}$ & $95(12.9)$ & $32(4.4)$ & $16(2.3)$ & $20(3.2)$ & $21(4.1)$ & $10(2.3)$ & $11(3.2)$ & $2(0.9)$ & 0 & 0 \\
\hline $\begin{array}{l}\text { All malignant neoplasms (except non-melanoma skin } \\
\text { cancer) }\end{array}$ & $6(0.8)$ & $1(0.1)$ & $1(0.1)$ & $1(0.2)$ & $2(0.4)$ & $1(0.2)$ & 0 & 0 & 0 & 0 \\
\hline Depression/suicide/self-injury & $86(11.7)$ & $40(5.4)$ & $24(3.4)$ & $14(2.3)$ & $14(2.7)$ & $4(0.9)$ & $4(1.2)$ & $4(1.8)$ & 0 & 0 \\
\hline Death & $11(1.5)^{\mathrm{c}}$ & $2(0.3)$ & $1(0.1)$ & $2(0.3)$ & $2(0.4)$ & $2(0.5)$ & 0 & 0 & 0 & 0 \\
\hline
\end{tabular}

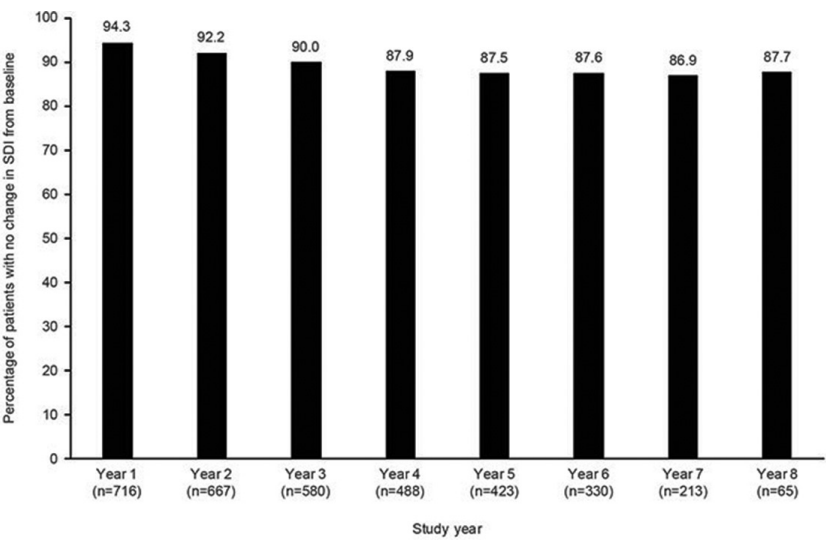

Acknowledgements: Study funded by GSK. Emma Hargreaves, MA, Fishawack Indicia Ltd, UK, provided editorial assistance funded by GSK.

Disclosure of Interest: R. Van Vollenhoven Grant/research support from: GSK, Consultant for: GSK, S. Navarra Speakers bureau: GSK, R. Levy Employee of: BLISS-52 investigator and GSK employee since, ${ }^{2018} \mathrm{M}$. Thomas Grant/research support from: GSK, Consultant for: GSK, A. Heath Shareholder of: GSK, Employee of: GSK, T. Lustine Shareholder of: GSK, Employee of: GSK, A. Adamkovic Shareholder of: GSK, Employee of: GSK, J. Fettiplace Shareholder of: GSK, Employee of: GSK (at the time of study), M. L. Wang Shareholder of: GSK, Employee of: GSK, B. Ji Shareholder of: GSK, Employee of: GSK, D. Roth Shareholder of: GSK, Employee of: GSK DOI: 10.1136/annrheumdis-2018-eular.3306

\section{OP0253 A PHASE III RANDOMISED, DOUBLE-BLIND, PLACEBO- CONTROLLED STUDY TO EVALUATE THE EFFICACY AND SAFETY OF ABATACEPT OR PLACEBO ON STANDARD OF CARE IN PATIENTS WITH ACTIVE CLASS III OR IV LUPUS NEPHRITIS}

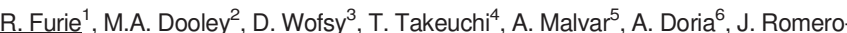

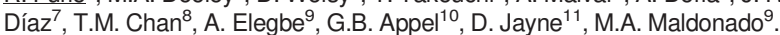
${ }^{1}$ Northwell Health, New York; ${ }^{2}$ University of North Carolina at Chapel Hill, Chapel Hill; ${ }^{3}$ University of California San Francisco, San Francisco, USA; ${ }^{4}$ Keio University, Tokyo, Japan; ${ }^{5}$ Hospital Fernández, Buenos Aires, Argentina; ${ }^{6}$ University of Padua, Padua, Italy; ${ }^{7}$ Instituto Nacional de Ciencias Médicas y Nutrición, Mexico City, Mexico; ${ }^{8}$ University of Hong Kong, Hong Kong, Hong Kong; ${ }^{9}$ Bristol-Myers Squibb, Princeton; ${ }^{10}$ Columbia University Medical Center, New York, USA;

${ }^{11}$ University of Cambridge, Cambridge, UK

Background: The tenets of novel treatment strategies for active class III or IV lupus nephritis $(\mathrm{LN})$ aim to improve renal response rates as well as the speed, robustness and durability of responses; decrease extra-renal SLE disease activity; reduce glucocorticoid exposure; ensure tolerability and provide acceptable treatment-related safety profile.

Objectives: Compare efficacy and safety of IV abatacept (ABA), a selective T cell co-stimulation modulator, vs placebo (pbo), on background therapy for active proliferative LN.

Methods: This was a 24-mth, randomised, Phase III, multicentre, double-blind study with an open-ended, blinded long-term extension. Patients (pts) were randomised to pbo or ABA IV $30 \mathrm{mg} / \mathrm{kg}$ for $3 \mathrm{mths}$, followed by ABA 10 mg/kg every 4 wks on a background of mycophenolate and glucocorticoids. The primary endpoint, complete response (CR) at 1 year, was a composite measure that required maintenance of glomerular filtration rate, urine protein-to-creatinine ratio
(UPCR) $\leq 0.5$, absence of urinary cellular casts and prednisone $\leq 10 \mathrm{mg} /$ day. We report $\mathrm{Yr} 1$ data and available post-Yr 1 data for all pts, all double-blind.

Results: 405 pts were randomised ( $A B A n=202$; pbo $n=203$ ). At baseline, mean age was 33 years, mean UPCR $=3.78$, mean serum creatinine $=0.93 \mathrm{mg} / \mathrm{dL}$ and mean GFR=95 mL/min. $\mathrm{Yr} 1$ study completion rates were $A B A 77 \%$, pbo $79 \%$; fewer ABA pts discontinued during Yr 2 (ABA 14\%, pbo 22\%) and beyond. There were no significant differences between treatment arms in the proportion of pts with CR after 52 wks of treatment (ABA $35.1 \%$, pbo $33.5 \%, p=0.73$; primary endpoint). Achievement of sustained CR (2 successive visits) occurred earlier and more frequently in ABA-treated pts (figure 1). These benefits were driven by improvement in proteinuria which was seen as early as Day 85 (adjusted mean change in UPCR ABA -2.50, pbo -2.00; adjusted difference from pbo [95\% $\mathrm{Cl}]-$ $0.50[-0.84,-0.16])$ and was sustained beyond $\operatorname{Yr} 2$ (Yr 2: ABA -3.13, pbo -2.72; adjusted difference from pbo $[95 \% \mathrm{Cl}]-0.41[-0.79,-0.03])$. There was no negative impact of $A B A$ on renal function (eGFR). Few non-renal adjudicated BILAG $A$ or $B$ events occurred in $\operatorname{Yr} 1$ ( $A B A=13$ [BILAG $A=0$ ], pbo=12 [BILAG A=2]). Safety in $\mathrm{Yr} 1$ was consistent with the known profile of $A B A$ (serious adverse event [SAE] rate ABA 24\%, pbo 19\%). SAE rates after Yr 1 improved (ABA 6\%, pbo 13\%). The death rate was similar at $\operatorname{Yr} 2$ (ABA 7, pbo 6). Improvements in SLE-related pharmacodynamic markers ( $C 3, C 4$ and anti-dsDNA auto $A b)$ were more sustained in ABA-treated pts.

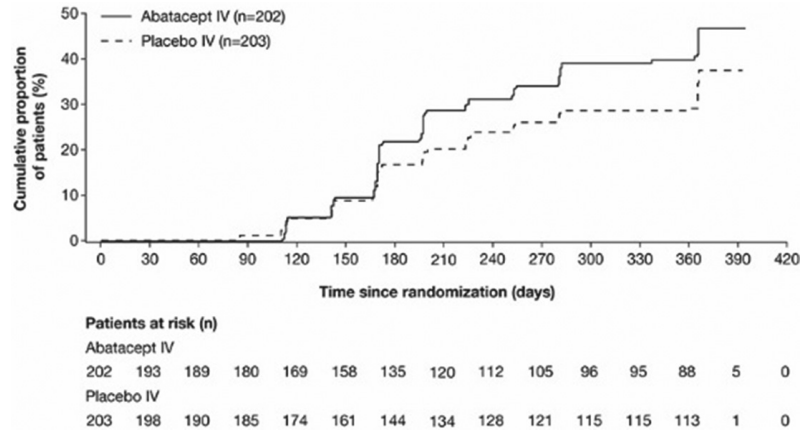

Abstract OP0253 - Figure 1 Kaplan-meier plot of time to first sustained complete renal response during year 1 of double-blind period: all randomised and treated patients

Conclusions: The study failed to meet its primary endpoint of higher CR rate in pts with active class III or IV LN after 1 year of abatacept treatment. Abatacepttreated pts had more rapid improvement in proteinuria, which led to earlier, sustained CR. There was a favourable safety profile extending beyond 2 years of treatment.

Disclosure of Interest: R. Furie Grant/research support from: Bristol-Myers Squibb, Consultant for: Bristol-Myers Squibb, M. Dooley Consultant for: BristolMyers Squibb, D. Wofsy Consultant for: GlaxoSmithKline, Novartis, Celgene UCB, Sanofi, T. Takeuchi Grant/research support from: Bristol-Myers Squibb, Chugai Pharmaceutical Co, Daiichi Sankyo, Takeda, Teijin Pharma, AbbVie, Asa hikasei Pharma, Mitsubishi Tanabe Pharma Co., Pfizer,and Taisho Toyama Pharmaceutical Co., Eisai, AYUMI Pharmaceutical Corporation, Nipponkayaku Consultant for: AstraZeneca, Eli Lilly, Novartis, Mitsubishi Tanabe Pharma Co. Abbivie, Nipponkayaku, Janssen, Astellas Pharma,Taiho Pharmaceutical, Speakers bureau: AbbVie,Bristol-Myers Squibb, Chugai Pharmaceutical, Mitsubishi Tanabe Pharma Co., Pfizer, and Astellas Pharma, and Diaichi Sankyo, A. Malvar: None declared, A. Doria Consultant for: GSK, Pfizer, Eli Lily, Bristol-Myers Squibb, Speakers bureau: GSK, Pfizer, Eli Lily, Bristol-Myers Squibb, J. RomeroDíaz: None declared, T. Chan Grant/research support from: Astellas, Consultant for: Astellas, Novartis, Boehringer Ingelheim, Aurinia, A. Elegbe Employee of: Bristol-Myers Squibb, G. Appel Grant/research support from: Bristol-Myers Squibb, D. Jayne Grant/research support from: GSK, Roche, Sanofi, Consultant 
for: Aurinia, Boehringer, Chemocentryx, CSL, GSK, Inflx, Medimmune, Takeda, Sanofi, M. Maldonado Shareholder of: Bristol-Myers Squibb, Employee of: BristolMyers Squibb

DOI: 10.1136/annrheumdis-2018-eular.3451

\section{OP0254 A PROPENSITY SCORE-MATCHED (PSM) ANALYSIS OF ORGAN DAMAGE IN PATIENTS WITH SYSTEMIC LUPUS ERYTHEMATOSUS (SLE) FROM THE POOLED BLISS LONG-TERM EXTENSION (LTE) TRIALS VERSUS THE TORONTO LUPUS COHORT (TLC)}

M. Urowitz ${ }^{1}$, R.L. Ohsfeldt ${ }^{2}$, R.C. Wielage ${ }^{2}$, J.J. Dever ${ }^{2}$, M. Zakerifar ${ }^{2}$, Y. Asukai ${ }^{3}$, S. Ramachandran ${ }^{4}$, A.V. Joshi ${ }^{4} .{ }^{1}$ Centre for Prognosis Studies in Rheumatic Diseases, Toronto Western Hospital, Toronto, ON, Canada; ${ }^{2}$ Medical Decision Modeling Inc., Indianapolis, IN, USA; ${ }^{3}$ Value Evidence and Outcomes, GSK, Brentford, UK; ${ }^{4}$ Value Evidence and Outcomes, GSK, Philadelphia, PA, USA

Background: A pooled analysis of the open-label BLISS LTE studies (BEL112233/BEL112234) reported low levels of organ damage accrual (measured by Systemic Lupus International Collaborating Clinics [SLICC]/American College of Rheumatology Damage Index [SDI]) in patients who received belimumab (BEL) plus standard therapy (SoC) over a 5 year period. However, the LTE studies had no SoC arm. This post-hoc study (206347) used PSM to match BLISS LTE patients to TLC patients to define a SoC treatment comparison cohort. Objectives: To assess damage accrual in patients with SLE treated with BEL plus SoC compared with PSM patients from the TLC treated with SoC alone. Methods: This analysis compared the mean SDI change from baseline (over 5 years), time to SDI event (on all patients with $>1$ year follow-up), and magnitude of year-to-year SDI change (over 5 years), from baseline to Year 5 in patients treated with BEL plus SoC (pooled United States [US] and non-US data from the BLISS LTE studies), and SoC alone. Patients in the LTE and TLC were 1:1 PSM based on 16 clinical variables with a propensity score calliper $\pm 20 \%$. Regression augmented inverse propensity score weighting (IPSW) tested the robustness of the PSM results.

Results: For the 5 year analysis, 181 LTE patients were matched to 181 TLC patients (mean bias $3.8 \%$ ) from a larger pool of 973 patients (BLISS LTE $n=592$; TLC $n=381$ ). Time-to-event PSM resulted in 323 LTE and 323 TLC patients (mean bias $3.7 \%$ ) from a larger pool of 1541 patients (BLISS LTE $n=949$; TLC $\mathrm{n}=592$ ). The mean SDI score change from baseline in the BEL group was 0.265 (95\% confidence interval [Cl]: $0.180,0.350)$ compared with 0.718 (95\% Cl: 0.547 , 0.889 ) in the SoC group, resulting in a BEL treatment effect of -0.453 fewer SDI units $(95 \% \mathrm{Cl}:-0.646,-0.260 ; \mathrm{p}<0.001)$ over 5 years compared with SoC alone. The IPSW model produced similar results $(-0.374,95 \% \mathrm{Cl}:-0.512,-0.236$; $\mathrm{p}<0.001)$. Patients treated with $\mathrm{BEL}$ were $60 \%$ less likely to progress to a higher SDI score over any given year of follow-up compared with SoC patients (hazard ratio $0.397,95 \% \mathrm{Cl}: 0.275,0.572 ; \mathrm{p}<0.001)$. A patient receiving $\mathrm{BEL}$ has a $3.1 \%$ annual probability of organ damage progression compared with a $7.5 \%$ annual probability with SoC. Among the 646 time-to-event matched patients, there were 49 increases in SDI over the first 5 years in the BEL group and 102 in the SoC group. Of these, $4.1 \%(n=2 / 49)$ of the BEL group had an SDI increase $>2$ compared with $25.5 \%$ ( $n=26 / 102)$ of the SoC group. Therefore, for patients who experienced any increase, the likelihood of experiencing $\mathrm{a} \geq 2$ point SDI increase was 6 -times greater in the SoC group (25.5/4.1=6.22; $\mathrm{p}=0.002)$.

Conclusions: This PSM analysis demonstrates that BEL plus SoC reduces, and slows the rate of organ damage progression and reduces the magnitude of progression compared with SoC alone.

Acknowledgements: Study funded by GSK. Emma Hargreaves, MA, of Fishawack Indicia Ltd, UK, provided editorial assistance funded by GSK.

Disclosure of Interest: M. Urowitz Grant/research support from: GSK, Consultant for: GSK, R. Ohsfeldt Employee of: GSK contractors with Medical Decision Modelling Inc., R. Wielage Employee of: GSK contractors with Medical Decision Modelling Inc., J. Dever Employee of: GSK contractors with Medical Decision Modelling Inc., M. Zakerifar Employee of: GSK contractors with Medical Decision Modelling Inc., Y. Asukai Shareholder of: GSK, Employee of: GSK, S. Ramachandran Shareholder of: GSK, Employee of: GSK, A. Joshi Shareholder of: GSK, Employee of: GSK

DOI: 10.1136/annrheumdis-2018-eular.3319

\section{OP0255 \\ IDENTIFICATION OF CLINICAL AND SEROLOGICAL PREDICTIVE FACTORS OF RESPONSE TO RITUXIMABTREATMENT IN SYSTEMIC LUPUS ERYTHEMATOSUS (SLE) PATIENTS}

H. Sánchez Pérez ${ }^{1}$, D. Isenberg ${ }^{2} .{ }^{1}$ Rheumatology, Hospital Universitario De Canarias, La Laguna, Spain; ${ }^{2}$ Centre for Rheumatology Division of Medicine, University College London, London, UK

Background: Response to Rituximab (RTX) varies significantly between SLE patients. Ethnicity may play a role in these differences, and a possible relationship has been suggested between the clinical response to RTX and the presence of certain auto-antibodies (ab) (anti-ENA and anti-dsDNA ab) and C3 levels at baseline.

Objectives: The aim of this study was to identify biomarkers that could predict the response to RTX treatment in SLE patients.

Methods: This was a cross-sectional study of 121 SLE patients treated with RTX in UCLH between 2000 and 2016. Demographic, clinical and serological data were analysed. Disease activity was evaluated using the BILAG index. Patients were categorised as 'Responders' if all or some of the As and Bs from the BILAG score at the time the RTX was given were lost at 6 and at 12 months, and as 'NonResponders' if none of the As and Bs were lost. Relapse after RTX treatment was defined as development of a new BILAG Grade A or B in any system. A uni and multivariate regression analysis were performed to identify predictive factors of response to RTX utilising a combination of clinical and biological markers.

Results: At 6 and at 12 months, $85 \%$ and $70 \%$ respectively of our patients had responded clinically to the RTX treatment. $24 \%$ of patients relapsed during the year after RTX. In the univariate analysis, constitutional symptoms at diagnosis (crude OR (95\% C); 5.66 (1.53-20.88), $\mathrm{p}=0.009)$ and the absence of musculoskeletal disease at the time of RTX $(0.27,(0.09-0.81), \mathrm{p}=0.019)$ were related to response at 6 months. In the multivariate analysis, both remained significant, (adjusted OR $(95 \% \mathrm{Cl}])$ : 5.33 (1.39-20.41), $\mathrm{p}=0.014$ and $0.26(0.08-0.81)$, $\mathrm{p}=0.021$ respectively. With respect to the response at 12 months, in the univariate analysis the presence of arthritis as the main indication for RTX (3.16 (1.31-7.58), $\mathrm{p}=0.010)$, the absence of renal disease at diagnosis $(0.36(0.15-0.86), \mathrm{p}=0.022)$ and of cardiorespiratory disease at the time of RTX $(0.29(0.09-0.89), p=0.031)$ less than one anti-ENA ab $(0.28(0.12-0.66), p=0.003)$, low levels of $\mathrm{C} 3$ at diagnosis $(0.29(0.09-0.89), p=0.031)$, increased anti-dsDNA ab levels $(0.38(0.17-$ $0.89), p=0.025)$ and decreased $\mathrm{C} 3$ levels $(0.27(0.11-0.63), p=0.002)$ before RTX were related to the response. In the multivariate analysis, only the absence of more than one anti-ENA showed significance $(0.30(0.11-0.82), p=0.020)$. Having more than one anti-ENA was related to relapse (3.30 (1.36-8.05), $p=0.009)$, while having arthritis as the main indication for RTX therapy was associated with a lower risk of flare $(0.26(0.10-0.64), p=0.004)$. On the multivariate analysis, having arthritis remained significant $(0.29(0.11-0.75), p=0.010)$

Conclusions: There is a relation between the presence of more than one antiENA $a b$ and a worse response to treatment at 12 months and a higher risk of flaring. Having arthritis at the time of RTX leads to a negative response at 6 months but a lower risk of flare before 1 year.

Disclosure of Interest: None declared

DOI: 10.1136/annrheumdis-2018-eular.2852

\begin{tabular}{|l|l}
\hline OP0256 & HYDROXYCHLOROQUINE REDUCES RISK OF INCIDENT \\
DIABETES MELLITUS IN PRIMARY SJÖGREN \\
SYNDROME PATIENTS: A PROPENSITY SCORE \\
MATCHED POPULATION-BASED COHORT STUDY
\end{tabular}

W.-S. Chen ${ }^{1 *}$, C.-Y. Tsai ${ }^{1}$, C.-C. chang ${ }^{2} .{ }^{1}$ Rheumatology, Taipei Veterans General Hospital; ${ }^{2}$ Rheumatology, Taipei medical Hospital, Taipei, Taiwan, Province of China

Background: $\mathrm{HCQ}$ is an antimalarial drug that is widely prescribed for the treatment of Sjögren syndrome. Glucocorticoids may alter glucose metabolism and contribute to diabetes mellitus. Treatment for primary Sjögren syndrome (SS) sometimes requires glucocorticoids that may worsen glucose homoeostasis. $\mathrm{HCQ}$ can reduce diabetes risk in SLE and RA.

Objectives: This study aimed to investigate the association of HCQ use and diabetes mellitus risk in primary SS patients.

Methods: This nationwide, population-based cohort study was conducted using the Taiwan National Health Insurance Research Database. In the period 200213,7311 newly diagnosed primary SS patients were identified after excluding those with a previous diagnosis of RA, SLE or diabetes mellitus. The propensity score matched 4874 patients with at least 6 month hydroxychloroquine exposure after diagnosis and 2437 patients without. Incidence of diabetes mellitus was identified as a new diagnostic code using a diabetes mellitus-specific medication. Results: Four hundred and ninety-seven newly diagnosed diabetes mellitus patients were identified among primary SS patients (4874 had taken HCQ and 2437 had never taken HCQ), with an average follow-up period of 4.9 years. Compared with patients without $\mathrm{HCQ}$ treatment, the hazard ratio (HR) of diabetes 